\title{
Biochemical Markers of Bone Metabolism in Relation to Adrenocortical and Growth Suppression During the Initiation Phase of Inhaled Steroid Therapy
}

\author{
SENJA KANNISTO, MATTI KORPPI, PEKKA ARIKOSKI, KYLLIKKI REMES, AND \\ RAIMO VOUTILAINEN
}

Department of Paediatrics, Kuopio University Hospital, Kuopio, Finland

ABSTRACT

\begin{abstract}
Growth suppression is usually most evident during the first year of inhaled steroid therapy. Steroid-induced changes in bone metabolism may contribute to this growth suppression. The aim of the present study was to evaluate the changes in biochemical markers of bone metabolism in relation to adrenal and growth suppression during the initiation phase of inhaled steroid therapy. Seventy-five school-aged children with new asthma were enrolled into budesonide (BUD, $n=30$ ), fluticasone propionate (FP, $n=30$ ) or cromone (CROM, $n=15$ ) treatment groups. BUD dose was $800 \mu \mathrm{g} / \mathrm{d}$ during the first two months and 400 $\mu \mathrm{g} / \mathrm{d}$ thereafter. The respective FP doses were 500 and $200 \mu \mathrm{g} / \mathrm{d}$. Biochemical markers of bone metabolism were measured before treatment and after 2 and 4 mo of therapy. In the control (CROM) group, the mean concentrations of serum osteocalcin (OC), carboxyterminal propeptide of type I procollagen (PICP) (formation markers) and type I collagen carboxyterminal telopeptide (ICTP) (degradation marker) tended to increase. In the BUD group, OC and PICP decreased during the 4 mo by a mean of $23 \%$ ( $p<$ $0.001)$ and $15 \%(p<0.05)$, respectively, while ICTP did not change significantly. In the FP group, OC and ICTP decreased during the first 2 mo by a mean of $19 \%(p<0.01)$ and $21 \%(p$ $<0.01$ ), respectively, returning to the pretreatment level at $4 \mathrm{mo}$, while PICP tended to increase during the 4 mo $(14 \%, p=0.12)$.
\end{abstract}

In the steroid treated children whose height SD score decreased during the first 12 mo of therapy, both OC and PICP decreased during the first 4 mo by a mean of $20 \%(p<0.01)$ and $21 \%(p$ $<0.001$ ), respectively. In those children who had no growth suppression, the changes were not significant: $-4 \%$ in $\mathrm{OC}$ and $+13 \%$ in PICP. Furthermore, in children who developed evidence of adrenocortical suppression (on the basis of a low-dose ACTH test), OC decreased more $(23 \%, p<0.01)$ than in those with normal adrenocortical function $(10 \%, p=0.06)$. In conclusion, both inhaled BUD and FP caused dose-dependent effects on biochemical markers of bone metabolism. The children who developed growth or adrenocortical suppression were likely to have changes also in bone metabolism. (Pediatr Res 52: 258262, 2002)

BUD, Budesonide

\section{Abbreviations}

CROM, Cromones (cromoglycate and nedocromil)

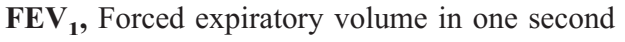

FP, Fluticasone propionate

ICTP, Type I collagen carboxyterminal telopeptide

OC, Osteocalcin

PICP, Carboxypropeptide of type I procollagen
Asthmatic children treated with inhaled steroids seem to attain normal adult height (1). Despite this, inhaled steroids may at least temporarily suppress adrenocortical function (2, $3)$, growth $(4,5)$, and bone metabolism $(6,7)$. Glucocorticoids affect calcium metabolism $(8,9)$, and they can reduce bone formation by impairing the function of osteoblasts (10). Therefore, long-term use of inhaled steroids can cause osteopenia, at least in adults $(11,12)$. There is a difference in the dose-

Correspondence and reprint requests: Senja Kannisto, M.D., Department of Paediatrics, Kuopio University Hospital, P.O. Box 1777, FIN-70211 Kuopio, Finland; e-mail: senja.kannisto@kuh.fi

DOI: 10.1023/01.PDR.0000020642.79983.AC response relation between efficacy and systemic adverse effects of inhaled steroids. A plateau in the efficacy is reached at relatively low doses (13), while a linear relation between the dose and the effects on the adrenocortical function and bone metabolism continues for much higher doses (14).

OC, the most abundant noncollagenous protein in bone matrix, is produced mainly by osteoblasts. Therefore, it has been used as a marker of osteoblastic activity $(15,16)$. Bone formation can be evaluated also by measuring serum concentrations of PICP, which is cleaved from type I procollagen during collagen synthesis (17). Collagen breakdown products, such as serum ICTP, have been used as an indicator of bone matrix degradation (18-20). 
In the present study, we followed serum OC, PICP, and ICTP during the first 4 mo of inhaled steroid therapy. During the first $2 \mathrm{mo}$, we used the maximal effective steroid doses, where after the doses were reduced to the conventional level. Our aim was to evaluate the changes in bone metabolism in relation to growth and adrenocortical function. We hypothesized that the children who developed adrenocortical or growth suppression during inhaled steroid therapy will also have altered bone metabolism.

\section{METHODS}

Subjects and study protocol. The study population consisted of 75 consecutively admitted children more than 5 years old with newly diagnosed asthma who were starting their first period of maintenance medication. The adrenocortical function and growth characteristics of the same patient group have been reported in detail previously (3). The physical activity of the children was normal, and they were able to take a part in normal sport activities at school and in leisure hours. None of the children had any other baseline disease except asthma, and none of them had used other medications (only antihistamines were allowed during pollen season). None of the children had used inhaled steroids during the preceding 12 mo. The mean age of the children was $9.5 \mathrm{y}$ (range 5.5-14.7), and 52\% were females. Sixty children were randomized to BUD $(n=30)$ or FP $(n=30)$ groups, and the remaining 15 children treated initially with CROM served as a control group. Based on the "step-down treatment policy," the steroid dose used was relatively high during the first two months of therapy, where after it was reduced to a conventional level. The BUD dose, given as dry powder (Pulmicort Turbuhaler, Astra, Södertälje, Sweden), was $800 \mu \mathrm{g} / \mathrm{d}$ during the first $2 \mathrm{mo}$ and $400 \mu \mathrm{g} / \mathrm{d}$ thereafter. Because FP has been found to be as effective as double doses of beclomethasone or BUD $(21,22)$, the used FP doses (Flixotide Diskus, Glaxo, Hertfordshire, UK) were 500 and 200 $\mu \mathrm{g} / \mathrm{d}$, respectively. The children in the CROM group received sodium cromoglycate $20-60 \mathrm{mg} / \mathrm{d}$ (Lomudal, Fisons Ltd, Cheshire, UK) or nedocromil $12 \mathrm{mg} / \mathrm{d}$ (Tilade, Fisons Ltd) throughout the 4-mo treatment period.

The children in the BUD and FP groups were examined at the beginning and after 2 and 4 mo of treatment. The children in the CROM group were examined at the beginning and after 4 mo of treatment. The growth of the children was followed for 12 mo after starting the asthma therapy. An experienced asthma nurse measured the heights of the children to the nearest $0.1 \mathrm{~cm}$ with a calibrated Harpenden stadiometer (Holtain Ltd, Crymych, Dyfed, UK) at each visit. The heights of the children were expressed as SD scores and weights as percentages in relation to the mean weight for height (23). The study was approved by the research ethics committee of Kuopio University Hospital, and the children and their parents gave an informed written consent for the study.

Bone marker measurements. We evaluated bone formation by determining serum PICP and serum OC, and bone matrix degradation by determining serum ICTP. The blood samples were withdrawn between 0800 and $1100 \mathrm{~h}$, and for individual patients the samples were taken at the same time on all occasions. All serum specimens were stored at $-70^{\circ} \mathrm{C}$ until analyzed. The samples of each patient were analyzed in the same assay. The intra-assay coefficients of variation (CV) were calculated from the actual series. PICP was determined by RIA (Orion Diagnostica, Espoo, Finland); the sensitivity of the method was $1.2 \mu \mathrm{g} / \mathrm{L}$, and the intra-assay CV was $11.0 \%$ for low and $10.6 \%$ for high values. The RIA for OC (OSCAtest, Brahms Diagnostica, Berlin, Germany) had the sensitivity of $1.8 \mu \mathrm{g} / \mathrm{L}$, and the intra-assay CV was $9.3 \%$ for low and $10.1 \%$ for high values. The sensitivity of the ICTP RIA (Orion Diagnostica) was $0.5 \mu \mathrm{g} / \mathrm{L}$, and its intra-assay $\mathrm{CV}$ was $14.1 \%$ and $15.1 \%$ for low and high values, respectively.

Efficacy of asthma treatment and adrenocortical function. At each visit, the FEV ${ }_{1}$ (Medicro 905, Medicro Ltd, Kuopio, Finland) was measured to define the efficacy of the treatment. Compliance was assessed at each visit by checking home monitoring diaries in which the subjects recorded the used medication doses. A low-dose ACTH test $\left(0.5 \mu \mathrm{g} / 1.73 \mathrm{~m}^{2}\right)$ was performed at the beginning and at 4 mo to evaluate the effect of the treatment on adrenocortical function. The test result was considered abnormal if the stimulated serum cortisol concentration was below $330 \mathrm{nmol} / \mathrm{L}$ (3).

Statistical analyses. The data were analyzed by SPSS version 10.0 (SPSS Inc., Chicago, IL, USA). Means, SD, and 95\% confidence intervals $(95 \% \mathrm{CI})$ were determined for continuous variables. For individual patients, the percentage changes of the bone markers were calculated from the baseline (before treatment) values. The statistical significance of the differences in continuous variables was calculated using the $t$ test or the analysis of variance, and the age, sex, and baseline values of bone markers were taken into account as confounding factors. The noncontinuous data were analyzed by the $\chi^{2}$-test.

\section{RESULTS}

The age, sex, height, weight, $\mathrm{FEV}_{1}$, and biochemical markers of bone metabolism in the three treatment groups at the beginning of the study are presented in Table 1. At the beginning, serum PICP was slightly higher in the BUD than in the FP or CROM groups $(p<0.05)$, while the other parameters did not differ. During the treatment, the symptoms of asthma resolved, and $\mathrm{FEV}_{1}$ improved significantly in both steroid groups. At $4 \mathrm{mo}, \mathrm{FEV}_{1}$ was above the baseline in the BUD by a mean of $8.4 \%(95 \% \mathrm{CI}, 3.2-13.6 ; p<0.01)$, and $5.4 \%(95 \%$ CI, $1.6-9.1 ; p<0.01)$ above the baseline in the FP group (there were no differences between the steroid groups). In the CROM group, $\mathrm{FEV}_{1}$ was below the baseline level by a mean of $1.5 \%(95 \% \mathrm{CI},-6.1$ to $3.1 ; \mathrm{NS})(p<0.05$ versus both steroid groups).

Biochemical markers of bone metabolism. The percentage changes of the markers of bone metabolism in the three treatment groups are presented in Figure 1. The age of the children and the baseline concentrations of the bone markers were taken into account as confounding factors in the statistical analyses. Of the markers of bone formation, OC decreased in the BUD and FP groups, while PICP decreased only in the BUD group. The bone degradation marker ICTP decreased in the FP group during the first 2 mo, returning close to the 
Table 1. Baseline age, sex, height, weight, FEV $, O C, P I C P$, and ICTP in the three treatment groups at the beginning of the study

\begin{tabular}{lccc}
\hline & BUD group $(n=30)$ & FT group $(n=30)$ & CROM group $(n=15)$ \\
\hline Age $(\mathrm{yr})$ & $9.3 \pm 2.2$ & $10.1 \pm 2.7$ & $8.7 \pm 2.6$ \\
Gender (female/male) & $17 / 13$ & $11 / 19$ & $11 / 4$ \\
Height SD score & $-0.07 \pm 0.90$ & $0.31 \pm 0.84$ & $-0.01 \pm 1.11$ \\
Weight $(\%)^{*}$ & $9.60 \pm 18.8$ & $11.1 \pm 19.5$ & $0.6 \pm 8.9$ \\
FEV $(\%$ of predicted) & $93 \pm 15$ & $92 \pm 11$ & $92 \pm 7$ \\
OC $(\mu \mathrm{mol} / \mathrm{L})$ & $19.1 \pm 6.7$ & $17.0 \pm 7.1$ & $15.0 \pm 5.6$ \\
PICP $(\mu \mathrm{mol} / \mathrm{L})$ & $353 \pm 135 \dagger$ & $265 \pm 101$ & $238 \pm 103$ \\
ICTP $(\mu \mathrm{mol} / \mathrm{L})$ & $11.9 \pm 3.8$ & $14.8 \pm 5.1$ & $11.5 \pm 2.9$ \\
\hline
\end{tabular}

Values are the mean \pm SD.

* The patients in the BUD and FT groups were heavier than those in the CROM group $(p<0.05)$.

$\dagger$ PICP was higher in the BUD than in the FT or CROM groups $(p<0.05)$. Otherwise, the groups did not differ significantly.

starting level by 4 mo; the changes in the BUD group were not significant. In the CROM group, all bone markers tended to increase slightly during the 4-mo follow-up period, but the
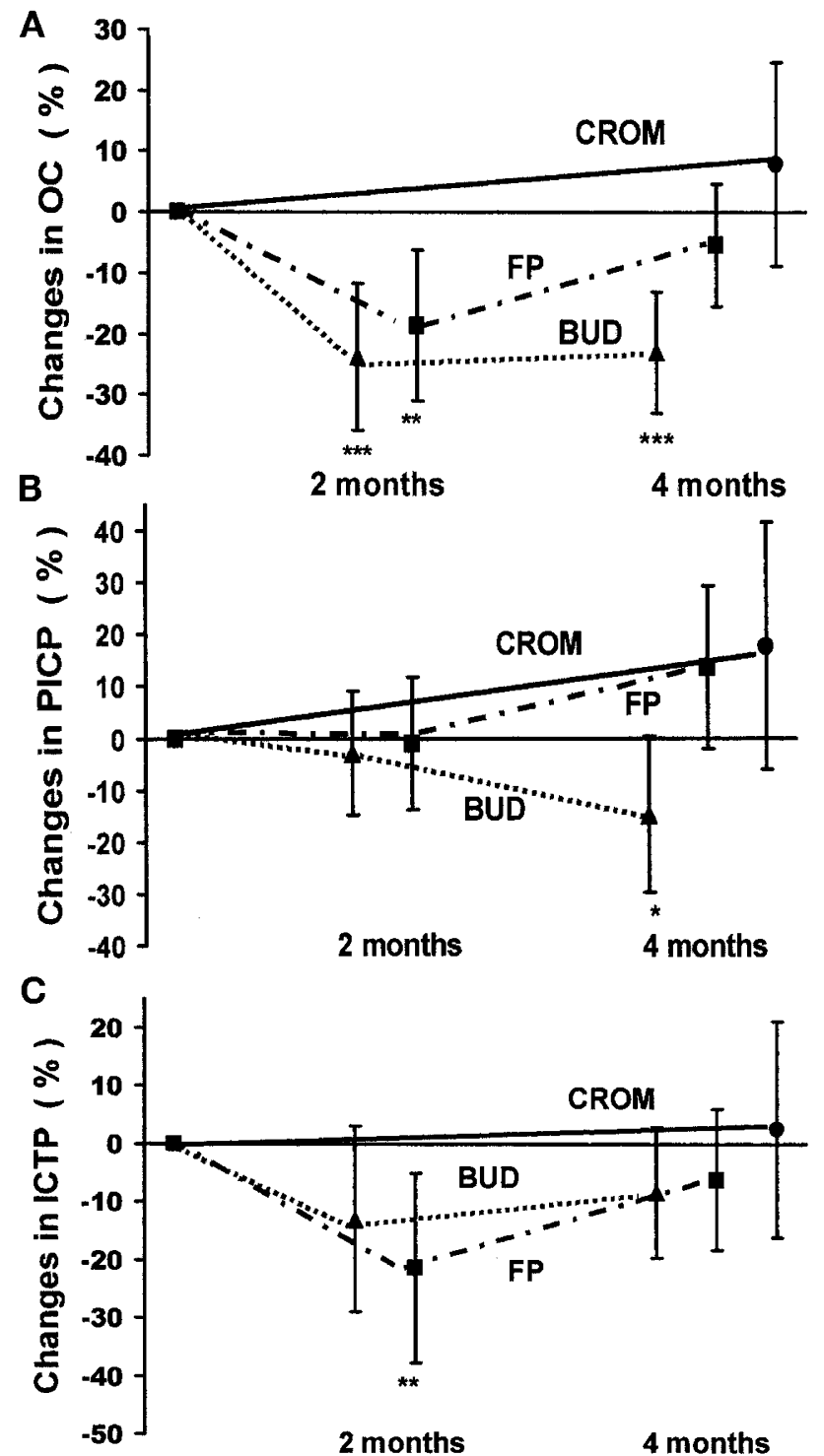

Figure 1. Percentage changes of OC $(a), \operatorname{PICP}(b)$, and ICTP $(c)$ after 2 and $4 \mathrm{mo}$ in the three treatment groups. The mean changes from the baseline with the $95 \%$ confidence intervals are shown. BUD group, $n=30$ (triangles), FP group, $n=30$, (squares), CROM group, $n=15$ (circles). $* p<0.05, * * p<$ $0.01, * * * p<0.001$ compared with the baseline values. changes were not significant. The changes of the bone markers were not different in boys compared with girls. The results were the same when girls older than $10 \mathrm{y}$ and boys older than 12 y were excluded from the analyses (to eliminate the possible influence of the physiologic late pubertal decrease in PICP and ICTP concentrations (24). Likewise, the severity of asthma did not have any effect on the baseline values or on the changes of bone marker concentrations.

Bone metabolism in relation to adrenocortical function and growth. At $4 \mathrm{mo}$, the low-dose ACTH-test result was normal in all CROM-treated children and abnormal in 14 $(23 \%)$ of the steroid-treated children. In the steroid-treated children with suppressed adrenocortical function, OC decreased by a mean of $23 \%(95 \% \mathrm{CI}, 9 \%$ to $36 \%, p<0.01)$ and PICP decreased $9 \%(95 \% \mathrm{CI},-27 \%$ to $9 \%$, NS), while in the children with a normal ACTH-test result the respective changes were $-10 \%(95 \% \mathrm{CI},-20 \%$ to $0 \%$, NS) and $+4 \%$ ( $95 \%$ CI, $-8 \%$ to $16 \%$, NS) (Fig. 2). In the children with an abnormal ACTH-test result, ICTP decreased by $2 \%$ (mean, NS), while in the children with a normal ACTH-test result it decreased $9 \%$ (NS).

The height SD score decreased during the 4-mo treatment period in $26(43 \%)$ and did not decrease in $34(57 \%)$ steroid treated children. OC decreased significantly in the children with decreasing height SD score $(16 \% ; p<0.01)$, while the changes in PICP were not significant (Table 2). Twenty-three

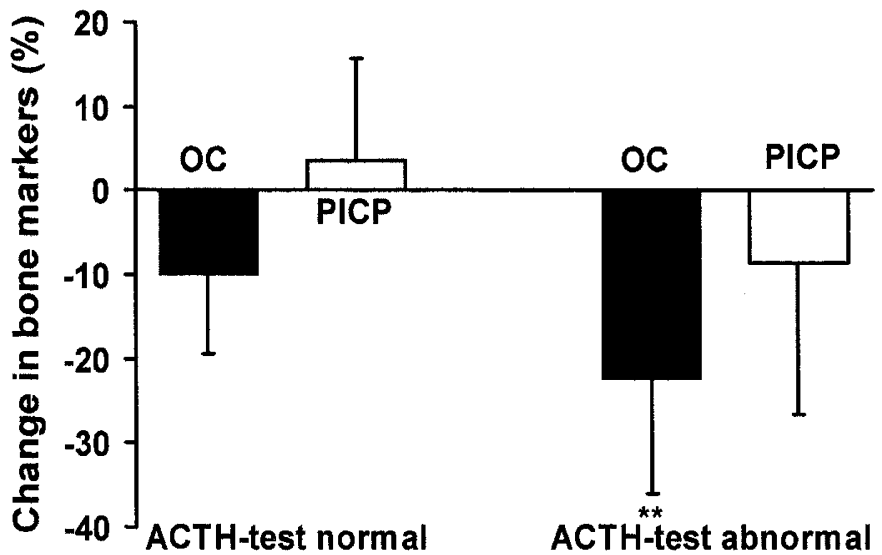

Figure 2. Percentage changes of bone formation markers OC and PICP during the 4-mo steroid treatment period in the children who had a normal (left; $n=46)$ and an abnormal (right; $n=14$ ) low-dose ACTH-test result. ** $p<$ 0.01 . 
of the original steroid-treated children used the same medication throughout the 12-mo follow-up period. The height SD score decreased in $13(57 \%)$ and did not decrease in $10(43 \%)$ of these children. The bone formation markers OC and PICP decreased significantly in the children with decreasing height SD score but not in those whose height SD score did not decrease (Table 2).

The changes in weight for height were small during the 4-mo observation period; mean change $+0.73 \%$ in the BUD, $+1.7 \%$ in the FP and $-0.6 \%$ in the CROM group (all nonsignificant). The weight for height increased during the 4-mo treatment period in $29(48 \%)$ and did not increase in $31(52 \%)$ of the steroid treated children. The changes in OC, PICP, and ICTP did not differ in these two patient groups.

\section{DISCUSSION}

In this prospective study in children with newly diagnosed asthma, both BUD and FP had measurable effects on biochemical markers of bone metabolism. The two bone formation markers, PICP and OC, decreased significantly during BUD treatment. The effects of FP, when used at half doses compared with BUD, were less prominent, and in the case of PICP, partly opposite. The changes in the bone degradation marker ICTP concentrations were less constant. All of these changes were steroid-dose dependent, but not explained by the age of the children, and they were associated with suppression of growth and adrenocortical function.

Of the markers of bone formation, OC seemed to be more sensitive than PICP to the effects of inhaled steroids. As OC is closely associated with bone mineralization (25), our data suggest that this later phase of bone formation is more prone to become depressed during corticosteroid treatment than the earlier phase of collagen synthesis. In the BUD-treated children, OC decreased at both high and low doses, while FP caused a significant decrease only at high doses. Accordingly, PICP decreased continuously at both BUD doses, whereas FP caused no decrease at all. Our findings are opposite to the results of Birkebaek et al. (26) and Hedlin et al. (27), who found no decrease in $\mathrm{OC}$ during inhaled steroid therapy. In these studies, the treatment period lasted less than 4 wk, which is perhaps too short to cause significant changes. Our findings are consistent with those of Sorva et al. (6), who treated their patients for 6 mo with BUD, and found a significant decrease in OC. Our data suggest that BUD diminishes bone formation, both mineralization and collagen synthesis, at least transiently, even at a dose of $400 \mu \mathrm{g} / \mathrm{d}$, whereas FP seems to diminish only the later mineralization phase of bone formation, and only at $500 \mu \mathrm{g} / \mathrm{d}$ doses. These results are consistent with the recent study of Reilly et al. (28), who found that FP is less likely than BUD to affect trabecular bone mineral density. On the other hand, during CROM treatment, both markers of bone formation tended to increase, probably reflecting normal agedependent growth and increase in bone mass $(29,30)$.

The bone matrix degradation product ICTP decreased in the FP group and did not change in the BUD group. However, not all experts consider serum ICTP a good marker of bone matrix degradation (31). Our ICTP results are opposite those of Hoekx et al. (32), who found a minor decrease in BUD users and a slight increase in FP users when the dose for both drugs was $400 \mu \mathrm{g} / \mathrm{d}$. However, in their study, all children had been treated with inhaled corticosteroids before entry, which may have influenced the baseline situation.

In both steroid groups, the changes of the bone resorption marker ICTP concentrations were in general parallel to those of the bone formation markers. This suggests that during inhaled steroid treatment, the coupling of bone formation and degradation is maintained, and the children on inhaled steroids may not be at a particular risk for osteopenia. In the present study, we did not measure bone mineral densities, as the expected changes during this short observation period would probably be minimal. This assumption is supported by a cross-sectional study of König et al. (33), who found no reduction in bone mineral density in beclomethasone-treated children, even though their OC levels decreased. Likewise, Martinati et al. (34) found no differences in bone mineral densities between bechlomethasone- and CROM-treated children. In two longitudinal studies in children lasting up to 18 mo, neither bechlomethasone nor FP had any significant effects on bone mineral density $(35,36)$. On the other hand, high cumulative doses of inhaled steroids have been associated with decreased bone mineral density in adults (12), and high inhaled steroid doses and short courses of oral corticosteroids have been found to reduce the acquisition of bone mineral in children (37).

Table 2. Percentage changes of serum bone marker concentrations in steroid treated children during the first 4 mo of inhaled steroid treatment presented separately in those whose height SD score decreased and did not decrease

\begin{tabular}{|c|c|c|c|c|c|c|}
\hline \multirow{3}{*}{$\frac{\text { Change in height SD score }}{\text { Decreased during the first } 4 \text { mo }(n=26)}$} & \multicolumn{6}{|c|}{ Percentage changes in bone markers during the first 4 mo of treatment } \\
\hline & \multicolumn{2}{|c|}{$\mathrm{OC}$} & \multicolumn{2}{|c|}{ PICP } & \multicolumn{2}{|l|}{ ICTP } \\
\hline & $\begin{array}{c}-16 \\
(-26 \text { to }-5)\end{array}$ & $p<0.01$ & $\begin{array}{c}-11 \\
(-23 \text { to }+2)\end{array}$ & NS & $\begin{array}{c}-5 \\
(-17 \text { to }+7)\end{array}$ & NS \\
\hline Did not decrease during the first 4 mo $(n=34)$ & $\begin{array}{c}-11 \\
(-22 \text { to }+1)\end{array}$ & NS & $\begin{array}{c}+9 \\
(-5 \text { to } 23)\end{array}$ & NS & $\begin{array}{c}-9 \\
(-22 \text { to } 4)\end{array}$ & NS \\
\hline Decreased during the first 12 mo $(n=13)^{*}$ & $\begin{array}{c}-20 \\
(-35 \text { to }-6)\end{array}$ & $p<0.01$ & $\begin{array}{c}-21 \dagger \\
(-28 \text { to }-14)\end{array}$ & $p<0.001$ & $\begin{array}{c}+3 \\
(-22 \text { to }+28)\end{array}$ & NS \\
\hline Did not decrease during the first 12 mo $(n=10)^{*}$ & $\begin{array}{c}-4 \\
(-30 \text { to }+22)\end{array}$ & NS & $\begin{array}{c}+13 \\
(-14 \text { to }+40)\end{array}$ & NS & $\begin{array}{c}-7 \\
(-38 \text { to }+23)\end{array}$ & NS \\
\hline
\end{tabular}

Values are mean percentage changes with $95 \%$ confidence intervals in parentheses.

* Only the children who were treated with the same drug throughout the 12 mo are included.

$\dagger$ The changes in PICP differed significantly from those whose height SD score did not decrease during the 12-mo follow-up $(p<0.01)$. 
The serum concentrations of the bone formation marker OC decreased especially in those children who developed biochemical evidence of adrenocortical suppression. Thus, children who are prone to develop adrenocortical suppression during inhaled steroid treatment seem also to be at increased risk for adverse effects on bone metabolism. Likewise, children with decreasing bone formation (OC or PICP decreased) at the initiation phase of inhaled steroid therapy are likely to be at risk for growth suppression. Of course, the complex phenomenon of growth is only partly mediated through bone metabolism, but it is known that normal growth and an increase of bone mass influence the markers of bone metabolism $(29,30$, 38 ). The bone marker concentrations are quite stable or increase slightly until the age of 12 to $14 \mathrm{y}$, where after they decrease to the adult level (24). The physiologic decrease in bone marker concentrations reported during late puberty does not seem to explain the changes seen in our steroid treated children because the exclusion of the oldest children did not change our finding. Growth suppression is usually most evident during the first year of inhaled steroid therapy $(5,39)$. Our previous (3) and present findings suggest that the changes in adrenocortical function and bone metabolism during the initiation phase of inhaled steroid therapy may predict growth suppression.

In conclusion, during the first 4 mo of inhaled steroid therapy, both BUD and FP had dose-dependent effects on biochemical markers of bone metabolism. OC was more apt than PICP to decrease during inhaled steroid treatment, suggesting that the mineralization phase of bone formation may be more sensitive to corticosteroid excess than the phase of collagen synthesis. The children who developed growth or adrenocortical suppression were likely also to have changes in bone metabolism during the initiation phase of inhaled steroid therapy.

Acknowledgments. The study was supported by the Finnish Foundation of Pediatric Research, Academy of Finland, Sigrid Juselius Foundation and Kuopio University Hospital.

\section{REFERENCES}

1. Agertoft L, Pedersen S 2000 Effect of long-term treatment with inhaled budesonide on adult height in children with asthma. N Engl J Med 343:1064-1069

2. Nicolaizik WH, Marchant JL, Preece MA, Warner JO 1994 Endocrine and lung function in asthmatic children on inhaled corticosteroids. Am J Respir Crit Care Med 150:624-628

3. Kannisto S, Korppi M, Remes K, Voutilainen R 2000 Adrenal suppression, evaluated by a low-dose ACTH-test, and growth in asthmatic children treated with inhaled steroids. J Clin Endocrinol Metab 85:652-657

4. Wolthers OD, Pedersen S 1991 Growth of asthmatic children during treatment with budesonide: a double blind trial. BMJ 303:163-165

5. Douill IJM, Freezer NJ, Holgate ST 1995 Growth of prepubertal children with mild asthma treated with inhaled beclomethasone dipropionate. Am J Respir Crit Care Med 151:1715-1719

6. Sorva R, Turpeinen M, Juntunen-Backman K, Karonen S-L, Sorva A 1992 Effect of inhaled budesonide on serum markers of bone metabolism in children with asthma. J Allergy Clin Immunol 90:808-815

7. Crowley S, Trivedi P, Risteli L, Risteli J, Hindmarsh PC, Brook CG 1998 Collagen metabolism and growth in prepubertal children with asthma treated with inhaled steroids. J Pediatr 132:409-413

8. Hahn TJ, Halstead LR, Baran DT 1981 Effects of short term glucocorticoid administration on intestinal calcium absorption and circulating vitamin D metabolite concentrations in man. J Clin Endocrinol Metab 52:111-115

9. Suzuki Y, Ichikawa Y, Saito E, Homma M 1983 Importance of increased urinary calcium excretion in the development of secondary hyperparathyroidism of patients under glucocorticoid therapy. Metabolism 32:151-156
10. Hanania NA, Chapman KR, Sturtridge WC, Szalai JP, Kesten S 1995 Dose-related decrease in bone density among asthmatic patients treated with inhaled corticosteroids. J Allergy Clin Immunol 96:571-579

11. Laatikainen AK, Kröger HPJ, Tukiainen HO, Honkanen RJ, Saarikoski SV 1999 Bone mineral density in perimenopausal women with asthma. Am J Respir Crit Care Med 159:1179-1185

12. Wong CA, Walsh LJ, Smith CJP, Wisniewski AF, Lewis SA, Hubbard R, Cawte S, Green DJ, Pringle M, Tattersfield AE 2000 Inhaled corticosteroid use and bonemineral density in patients with asthma. Lancet 355:1399-1403

13. Holt S, Suder A, Weatherall M, Cheng S, Shirtcliffe P, Beasley R 2001 Dose-response relation of inhaled fluticasone propionate in adolescents and adults with asthma: meta-analysis. BMJ 323:253-256

14. Lipworth BJ 1999 Systemic adverse effects of inhaled corticosteroid therapy: a systematic review and meta-analysis. Arch Intern Med 159:941-955

15. Brown JP, Malaval L, Chapuy MC, Delmas PD, Edouard C, Meunier PJ 1984 Serum bone GLA-protein: a specific marker for bone formation in postmenopausal osteoporosis. Lancet 1:1091-1093

16. Delmas PD 1990 Biochemical markers of bone turnover for the clinical assessment of metabolic bone disease. Endocrinol Metab Clin North Am 19:1-18

17. Parfitt AM, Simon LS, Villaneuva AR, Krane SM 1987 Procollagen type I carboxyterminal extension peptide in serum as a marker of collagen biosynthesis in bone: correlation with iliac bone formation rates and comparison with total alkaline phosphatase. J Bone Miner Res 2:427-436

18. Risteli L, Risteli J 1993 Biochemical markers of bone metabolism. Ann Med 25:385-393

19. Sorva R, Tähtelä R, Turpeinen M, Juntunen-Backman K, Haahtela T, Risteli L, Risteli J, Sorva A 1996 Changes in bone markers in children with asthma during inhaled budesonide and nedocromil treatments. Acta Paediatr 85:1176-1180

20. Risteli J, Elomaa I, Niemi S, Novamo A, Risteli L 1993 Radioimmunoassay for the pyridinoline cross-linked carboxy-terminal telopeptide of type I collagen: a new serum marker of bone collagen degradation. Clin Chem 39:635-640

21. Högger P, Rohdewald P 1988 Glucocorticoid receptors and fluticasone propionate. Rev Contemp Pharmacother 9:501-522

22. Ferguson AC, Spier S, Manjra A, Versteegh GA, Mark S, Zhang P 1999 Efficacy and safety of high-dose inhaled steroids in children with asthma: a comparison of fluticasone propionate with budesonide. J Pediatr 134:422-427

23. Sorva R, Perheentupa J, Tolppanen EM 1984 A novel format for a growth chart. Acta Paediatr Scand 73:527-529

24. Crofton PM, Wade JC, Taylor MRH, Holland CV 1997 Serum concentrations of carboxyl-terminal propeptide of type I procollagen, amino-terminal propeptide of type III procollagen, cross-linked carboxyl-terminal telopeptide of type I collagen, and their interrelationships in schoolchildren. Clin Chem 43:1577-1581

25. Eriksen EF, Brixen K, Charles P 1995 New markers of bone metabolism: clinical use in metabolic bone disease. Eur J Endocrinol 132:251-263

26. Birkebaek NH, Esberg G, Andersen K, Wolthers O, Hassager C 1995 Bone and collagen turnover during treatment with inhaled dry powder budesonide and beclomethasone dipropionate. Arch Dis Child 73:524-527

27. Hedlin G, Svedmyr J, Ryden A-C 1999 Systemic effects of a short course of betamethasone compared with high-dose inhaled budesonide in early childhood asthma. Acta Paediatr 88:48-51

28. Reilly SM, Hambleton G, Adams JE, Mughal MZ 2001 Bone density in asthmatic children treated with inhaled steroids. Arch Dis Child 84:183-184

29. Johansen JS, Giwercman A, Hartwell D, Nielsen CT, Price PA, Christiansen C, Skakkebaek NE 1988 Serum bone Gla-protein as a marker of bone growth in children and adolescents: correlation with age, height, serum insulin-like growth factor I, and serum testosterone. J Clin Endocrinol Metab 67:273-278

30. Trivedi P, Risteli J, Risteli L, Hindmarsh PC, Brook CGD, Mowat AP 1991 Serum concentration of the type I and III procollagen propeptides as biochemical markers of growth velocity in healthy infants and children and in children with growth disorders. Pediatr Res 30:276-280

31. Calvo MS, Eyre DR, Gundberg CM 1996 Molecular basis and clinical application of biological markers of bone turnover. Endocr Rev 17:333-368

32. Hoekx JCM, Hedlin G, Pedersen W, Sorva R, Hollingworth K, Efthimiou J 1996 Fluticasone propionate compared with budesonide: a double-blind trial in asthmatic children using powder devices at a dosage of $400 \mu \mathrm{g}$ /day. Eur Respir J 9:2263-2272

33. König P, Hillman L, Cervantes C, Levine C, Maloney C, Douglass B, Johnson L, Allen S 1993 Bone metabolism in children with asthma treated with inhaled beclomethasone dipropionate. J Pediatr 122:219-226

34. Martinati LC, Bertoldo F, Gasperi E, Micelli S, Boner AL 1996 Effect on cortical and trabecular bone mass of different anti-inflammatory treatments in preadolescent children with chronic asthma. Am J Respir Crit Care Med 153:232-236

35. Martinati LC, Bertoldo F, Gasperi E, Fortunati P, Lo Cascio V, Boner AL 1998 Longitudinal evaluation of bone mass in asthmatic children treated with inhaled beclomethasone dipropionate or cromolyn sodium. Allergy 53:705-708

36. Rao R, Gregson RK, Jones AC, Miles EA, Campbell MJ, Warner JO 1999 Systemic effects of inhaled corticosteroids on growth and bone turnover in childhood asthma: comparison of fluticasone with beclomethasone. Eur Respir J 13:87-94

37. Allen HDW, Thong IG, Clifton-Bligh P, Holmes S, Nery L, Wilson KB 2000 Effects of high-dose inhaled corticosteroids on bone metabolism in prepubertal children with asthma. Pediatr Pulmonol 29:188-193

38. Saggese G, Baroncelli GI, Bertelloni S, Cinquanta L, DiNero G 1993 Effects of long-term treatment with growth hormone on bone and mineral metabolism in children with growth hormone deficiency. J Pediatr 122:37-45

39. Saha MT, Laippala P, Lenko HL 1997 Growth of asthmatic children is slower during than before treatment with inhaled glucocorticoids. Acta Paediatr 86:138-142 